\title{
FUNGSI MUSIK ONDEL-ONDEL GRUP WIBAWA SAKTI DI DESA KEBON KOPI KABUPATEN BEKASI JAWA BARAT
}

\author{
Agung Wira Sentika Cahya \\ Institut Seni Indonesia Yogyakarta \\ E-mail : arjunaagung04@gmail.com
}

\begin{abstract}
ABSTRAK
Musik Ondel-ondel adalah sebuah kesenian tradisional masyarakat Betawi yang digunakan untuk mengiringi Ondel-ondel dalam kegiatan berkesenian khususnya di masyarakat Betawi. Seiring dengan perkembangan zaman saat ini keberadaannya tersebar di wilayah DKI Jakarta, Bogor, Depok, Tangerang, dan Bekasi. Instrumen yang digunakan biasanya menggunakan mp3 dan Instrumen tradisional seperti Tehyan, Kendang Tepak, Gong, Kempul dan satu buah gerobak kayu yang digunakan untuk menyimpan alat pengeras suara. Tetapi Grup kesenian Ondel-ondel Wibawa Sakti yang bermarkas di jalan Kyai Haji Fudholih, Desa Kebon Kopi, Cikarang Utara, Kabupaten Bekasi, Jawa Barat. tetap mempertahankan instrumen Betawi. Metode yang dipakai dalam penelitian ini adalah metode kualitatif pendekatan etnomusikologi dan sosiologi. Hasil penelitian menunjukan bahwa musik Grup Wibawa Sakti masih mempertahankan karakteristik tradisional ditengah masyarakat yang sudah ketergantungan dengan moderenisasi. Melalui Grup Wibawa Sakti kesenian Ondelondel menjadi media yang berfungsi sebagai perekonomian dan membuktikan bahwa fungsi Ondel-ondel sudah tidak lagi sebatas ritual saja tetapi sudah masuk ke wilayah ekonomi. Bentuk penyajian musik Ondel-ondel Grup Wibawa Sakti menggunakan instrumen tradisional tradisi.
\end{abstract}

Kata kunci : Ondel-ondel, Grup Wibawa Sakti, Fungsi, Bentuk Penyajian, Bekasi.

\section{ABSTRACT}

Ondel-ondel music is a traditional Betawi art that is used to accompany Ondel-ondel in art activities especially in the Betawi community. Along with the development of the current era, its existence is spread in the areas of DKI Jakarta, Bogor, Depok, Tangerang and Bekasi. The instruments used are usually mp3 and traditional instruments such as Tehyan, Kendang Tepak, Gong, Kempul and one wooden cart used to store loudspeakers. But the Ondel-ondel Wibawa Sakti art group based on Kyai Haji Fudholih Street, Kebon Kopi Village, North Cikarang, Bekasi Regency, West Java. while maintaining Betawi instruments. The method used in this study is a qualitative method of ethnomusicology and sociology approaches. The results showed that the music of the Wibawa Sakti Group still retained traditional characteristics in a society that was already dependent on modernization. Through the Wibawa Sakti Group, the Ondel-ondel art becomes a media that functions as an economy and proves that the Ondel-ondel function is no longer merely a ritual but has entered the economic area. The Wibawa Sakti Group's Ondel-ondel music presentation uses traditional traditional instruments.

Keywords $\quad$ : Ondel-ondel, Wibawa Sakti Group, Function, Presentation Form, Bekasi. 


\section{A. Latar Belakang}

Ondel-ondel merupakan sebuah boneka raksasa yang dimaknai masyarakat Betawi sebagai ritual sakral dan digunakan untuk ritualpersembahan kepada roh-roh leluhur. Boneka raksasa yang dikenal dengan nama ondel-ondel ini, pada awalnya masyarakat Betawi menyebutnya dengan sebutan barongan yang menjadi ciri khas budaya Betawi. Ondel-ondel terdaftar sebagai salah satu dari delapan ikon budaya Betawi yang diatur dalam Pergub No 11 tahun 2017 tentang ikon Budaya Betawi. Berdasarkan regulasi itu disebutkan bahwa secara filosofi ondel-ondel bermakna sebagai perlambang kekuatan yang memiliki kemampuan memelihara keamanan dan ketertiban, tegar, berani, tegas, jujur dan anti manipulasi. Seiring dengan perkembangan zaman ondel-ondel sudah tidak lagi menjadi benda yang sakral dan juga tidak lagi digunakan untuk ritual persembahan. Ondel-ondel masa kini tidak lebih hanya dijadikan hiasan atau digunakan sebagai mata pencaharian masyarakat Betawi.

Peran ondel-ondel dalam sejarahnya memang digunakan sebagai bentuk ritual untuk mengusir roh jahat, dan diimplementasikan ke dalam boneka tersebut sebagai wujud dari roh baik sebagai pengusirnya. Ritus yang dilakukan oleh masyarakat Betawi ini disebutkan masih berlangsung hingga tahun 1970-an. Sejak dulu kesenian ini dilakukan dengan cara diarak dengan sepasang boneka Ondelondel yang digerakan oleh manusia, dan diiringi dengan permainan musik dari ansambel Gambang Kromong.

Ondel-ondel yang menjadi salah satu identitas budaya Betawi pada akhirnya melalui suatu proses yang terus menerus dalam rangka pendefinisian kembali tradisi dan identitasnya yang tidak hanya sebagai jawaban terhadap proses otonomisasi yang diartikan orang Betawi dalam segala bidang kehidupan (politik, ekonomi, sosial, dan budaya, tetapi juga sebagai tuntutan komunikasinya yang sedang mengalami perubahan).

Kemajuan zaman yang sangat plastis dan signifikan menawarkan berbagai macam opsi perubahan-perubahan bagi keberlangsungan hidup masyarakat. Di tengah perkembangan teknologi yang berkembang saat ini, bentuk kesenian ondel-ondel bergeser dari bentuk asli sebagai ritual penolak bala menjadi sarana mengamen keliling. fenomena yang ada saat ini dimana banyak ditemui kesenian ondel-ondel yang tidak lagi menggunakan instrumen tradisinya melainkan saat ini kerap ditemui kelompok kesenian yang menggunakan mp3 populer seperti dangdut, dangdut koplo, lagu pop Indonesia dan lain sebagainya. walaupun demikian bukan berarti tidak ada lagi komunitas atau grup kesenian khususnya ondel-ondel yang 
mempertahankan bentuk kesenian layaknya pada bentuk tradisinya. Salah satu komunitas atau grup kesenian yang tetap mempertahankan bentuk kesenian ondelondel layaknya bentuk tradisinya ialah grup Wibawa Sakti.

Grup Wibawa Sakti merupakan sebuah kelompok kesenian ondel-ondel yang berada di Kampung Kebon kopi, Cikarang utara, Kabupaten Bekasi. Grup Wibawa Sakti ini dibentuk sejak lama serta satu-satunya grup kesenian ondelondel yang berada di wilayah Kampung Kebon Kopi. Grup kesenian ini menghadirkan kesenian ondel-ondel dengan cara memanfaatkan ondel-ondel untuk mengamen dari satu tempat ke tempat lainnya atau biasa disebut mengamen keliling. Zaman yang saat ini serba modern tidak membuat Grup Wibawa Sakti menghilangkan karakteristik ondel-ondel, justru mereka tetap mempertahankan instrumen tradisi betawi, hal ini sangat berbeda dengan grup ondel-ondel yang lainnya. Begitu juga dengan lagu yang biasa dibawakan oleh grup Wibawa Sakti diantaranya lagu-lagu khas betawi seperti ondel-ondel, sirih kuning, jali-jali, Sang Kodok dan kicir-kicir. Instrumen yang digunakan yaitu instrumen tradisional seperti Tehyan, Gendang Tepak, Gong Kempul, Ningnong, dan Kecrek. Beberapa instrumen serta alat pengeras suara yang digunakan saat mengamen keliling oleh grup wibawa sakti diangkut menggunakan gerobak kayu.

Teori Max Weber melakukan klasifikasi dari empat tipe tindakan yang dibedakan dalam konteks motif para pelakunya yaitu: Tindakan tradisional, Tindakan afektif, rasionalitas instrumental dan rasionalitas nilai. Teori tindakan sosial Max Weber berorientasi pada motif dan tujuan pelaku. Dengan menggunakan teori ini kita dapat memahami perilaku setiap individu maupun kelompok bahwa masingmasing memiliki motif dan tujuan yang berbeda terhadap sebuah tindakan yang dilakukan. Teori ini bisa digunakan untuk memahami tipe-tipe perilaku tindakan setiap individu maupun kelompok. dengan memahami perilaku setiap individu maupun kelompok, sama halnya kita telah menghargai dan memahami alasan-alasan mereka dalam melakukan suatu tindakan. Sebagaimana diungkapkan oleh Weber, cara terbaik untuk memahami berbagai kelompok adalah menghargai bentukbentuk tipikal tindakan yang menjadi ciri khasnya. Sehingga kita dapat memahami alasan-alasan mengapa warga masyarakat tersebut bertindak.

Melalui tipe teori ini dapat mengetahui bagaimana aktivitas yang dilakukan Grup Wibawa Sakti dalam kesenian Ondel-ondel tidak lepas dari pemikiran secara sadar bahwa mereka memiliki kapasitas atau kemampuan untuk 
melakukannya. Artinya untuk melakukan dan melestarikan kesenian Ondel-ondel sehingga bisa berjalan dan berkembang sampai saat ini, mereka telah memikirkannya secara sadar dan rasional bahwa memang mereka memiliki kapasitas untuk melakukannya, baik dari segi sumber daya manusianya maupun dari segi aspek yang lainnya yang disitu memiliki peran penting untuk dijadikan sebagai landasan pemikiran bahwa kegiatan tersebut bisa dilaksanakan.

\section{B. Metode Penelitian}

Penelitian ini menggunakan metode kualitatif. melalui participant observer yang merupakan bagian dari metode etnografi, realitas yang terjadi dalam perilaku kelompok Wibawa Sakti terhadap mengamen keliling dapat terlihat dan dapat dibedah secara mendalam. Cara tersebut digunakan melalui keterlibatan langsung antara peneliti dengan objek penelitian sehingga mampu menggali informasi yang mendalam dari subjek yang diteliti. Etnografi merupakan salah satu metode penelitian kualitatif yang mencoba mendeskripsikan analisis budaya berdasarkan kerja lapangan yang intensif. Metode etnografi dianggap mampu menjadi metode yang paling representative dalam mengungkapkan persoalan budaya ataupun fenomena sosial yang terjadi di masyarakat.
Metode kualitatif digunakan untuk mengungkap dan memahami suatu makna dibalik fenomena dan juga untuk mendapatkan wawasan tentang sesuatu yang belum banyak diketahui. Metode kualitatif ini nantinya akan dalam bentuk deskripsi analisis, yaitu suatu penelitian yang mengolah secara kualitatif, sedangkan metode deskriptif yaitu penyusunan laporan penelitian yang menyajikan datanya dengan mengadakan analisis atas subjek dengan mendeskripsikan secara sistematis dan disertai analisis terhadap subjek penelitian. Mendeskripsikan dan menganalisis secara lebih mendalam tentang dampak dari ondelondel keliling yang dilakukan Grup Wibawa Sakti terhadap keberlangsungannya.

\section{Hasil dan Pembahasan}

Sebagai salah satu grup yang melestarikan dan menjaga eksistensi dari kesenian Ondel-ondel Wibawa Sakti cukup berhasil dalam membentuk sebuah grup yang tetap menggunakan instrumen asli dari kesenian Ondel-ondel. Munculnya ide untuk mendirikan grup kesenian tidak lepas dari keresahan pendiri Wibawa Sakti akan menurunnya tingkat eksistensi kesenian Betawi pada saat ini serta mempertahankan kesenian yang dimiliki agar tidak ditinggalkan oleh masyarakat khususnya anak-anak muda. Kondisi ini yang 
menggetarkan hati Jumadi untuk membuat grup kesenian yang diberi nama Wibawa Sakti karena sudah banyaknya musikmusik pop yang sangat digandrungi oleh anak muda sekarang ini. Hal ini tidak terjadi di Bekasi saja tetapi hampir disetiap daerah juga mengalami kejadian yang hampir sama.

Berdasarkan keresahan dan fenomena yang terjadi sangatlah tepat Jumadi mendirikan Wibawa Sakti yang tetap mempertahankan musik asli dari kesenian Ondel-ondel. Dampak yang cukup signifikan adalah tidak hanya ondel-ondel saja yang terangkat tetapi pemain serta seniman yang membuat alat musik jadi eksis kembali dan Ondel-ondel yang merupakan salah satu kesenian Betawi menjadi tontonan wajib untuk masyarakat sekitarnya. Hal positif yang bisa didapatkan bukan itu saja, beberapa diantaranya adalah masyarakat menjadi tertarik lebih mengenal kesenian Ondel-ondel dengan begitu ketika masyarakat asli melestarikan sudah pasti orang luar Bekasi akan tertarik juga dengan kesenian yang ada didalamnya.

Fungsi seni sebagai sarana edukatif sangat melekat pada grup Wibawa Sakti, karena selain memperkenalkan dan menjaga eksistensi Ondel-ondel dalam prakteknya Wibawa Sakti juga memberikan sarana untuk pembelajaran lain. Jumadi memberikan edukasi lain selain pengetahuan memainkan alat musik tradisi
Betawi yaitu diantaranya belajar tentang pencak silat, palang pintu, dan lenong Betawi. Berbagai edukasi yang di suguhkan Wibawa Sakti ini sangat bermanfaat untuk anggotanya terutama anak-anak yang bergabung dan direkrut oleh Jumadi dengan latar belakang putus sekolah. Selain belajar tentang bagaimana tidak melakukan hal-hal negatif tetapi belajar mencari uang dengan halal serta belajar mempertahankan kesenian Betawi yang sangat jarang diminati oleh remaja saat ini. Meskipun tidak mengenyam pendidikan tinggi tetapi setidaknya tau akan budaya dan diarahkan kemana kesenian yang sudah mereka pelajari.

Fungsi seni secara umum adalah sebagai bentuk atau cara penyampaian ekspresi seseorang kepada orang lain dan lingkungannya. Seni sebagai unsur budaya tentu saja mempunyai fungsi dan peran yang berbeda dengan unsur budaya lain. Kaum fungsional mengatakan bahwa segala sesuatu akan dipertahankan keberadaannya jika sesuatu tersebut masih fungsional. Fungsi seni pertunjukan diantaranya adalah sebagai fungsi Religius, fungsi Sosial, fungsi Edukasi, fungsi Estetik, fungsi Ekonomi, fungsi Hiburan, dan fungsi Kesehatan. Fungsi musik Ondelondel Grup Wibawa Sakti biasanya digunakan untuk sarana Edukasi, Ekonomi, dan Hiburan.

a) Fungsi Edukasi 
Salah satu fungsi dari seni pertunjukan sebagai media pendidikan melalui transformasi nilai-nilai budaya yang ada di dalam seni pertunjukan. Maka seorang seniman dituntut untuk dapat berperan semaksimal mungkin atas peran yang diembannya. Seni pertunjukan sebagai media pendidikan sebenarnya sudah terkandung pada hakekat seni pertunjukan itu sendiri. Edukasi yang ada di Grup Wibawa Sakti ialah memberikan pembelajaran dan pemahaman kepada remaja bahwasannya kesenian tradisi harus dipertahankan dan diperkenalkan dan itu harus sudah ditanamkan sejak dini.

b) Fungsi Ekonomi

Ada beberapa yang menempatkan sebuah seni pagelaran selain sebagai alat untuk mendatangkan keuntungan, seni pertunjukan juga bisa dibuat sesuai dengan keperluan dan keinginan pembuatnya. Bentuk seni yang dipertunjukan harus mampu memenuhi harapan dari penikmatny, walaupun dalam berkesenian terkadang harus menyimpang dari norma estetis yang berlaku. Seni pertunjukan untuk memenuhi fungsi materi biasanya terjadi karena permintaan yang semakin meningkat. Grup Wibawa Sakti selain memberikan edukasi kepada kaum remaja juga memberikan finansial yang cukup dengan cara ngamen keliling dan acaraacara undangan lainnya bisa menambah pundi-pundi keungan bagi pribadi mereka. c) Fungsi Hiburan

Fungsi musik sebagai hiburan bisa dikaitkan dengan fungsi musik yang lain, karena hiburan merupakan suatu aktivitas yang di dalamnya terkait fungsi lain seperti, respon fisik yang mana dalam hiburan biasanya melahirkan gerakan alami pemain maupun penonton, kemudian ada pula kaitannya dengan fungsi musik sebagai integritas sosial yang mana hiburan dapat membuat warga berdatangan dan menjadi satu kesatuan dengan yang lain.

Kesenian Ondel-ondel memiliki karakter musik yang sederhana yang dapat dilihat dari instrumen yang diambil dari beberapa ansamble gambang kromong. Pertunjukan yang dihadirkan oleh Grup Wibawa Sakti yaitu dengan mengamen keliling dan terkadang juga mengisi acara di sebuah pesta besar atau event.

\section{Simpulan}

Musik Grup Musik Wibawa Sakti masih mempertahankan karakteristik tradisionalnya ditengah Masyarakat yang sudah ketergantungan dengan moderenisasi yang sangat pesat saat ini. Dengan kesenian Ondel-ondel lah Grup Wibawa Sakti mempertahankan dan mengenalkan keseniannya ke Masyarakat yang sudah mulai melupakan kesenian tradisi daerahnya dan Grup Wibawa sakti bisa memberikan edukasi kepada kalangan 
Masyarakat khususnya kalangan remaja yang mulai tidak peduli dengan kesenian tradisi, dengan tujuan edukasi lah anakanak remaja bisa terhindar dari tindakan kejahatan.

Kondisi perkembangan kesenian Ondel-ondel sedikit tergambarkan melalui Grup Wibawa Sakti yang menjadi salah satu media perekonomian melalui kata-kata tentang honor yang disertai edukasi untuk para pelaku kesenian Ondel-ondel. Ini membuktikan bahwa fungsi Ondel-ondel tidak lagi sebatas ritual saja, namun juga telah memasuki wilayah Ekonomi. Sisi lain dari kemunculan kesenian Ondel-ondel yang dimiliki Grup Wibawa Sakti pun merujuk pada dampak kreatifitasnya dalam mengembangkan musiknya.

\section{E. Daftar Pustaka}

Chaer, Abdul. 2015.Betawi Tempo Doeloe: Menelusuri Sejarah Kebudayaan Betawi. Jakarta: Masup.

Erwantoro, Heru. 2014. Etnis Betawi: Kajian Histori. Bandung: Balai Pelestarian Nilai Budaya.

Faizah, Nur. 2018. "Mobilitas Sosial dan Identitas Etnis Betawi", Journal of Geographical Studies.

Haryanto, 2015. Musik Suku Dayak: Sebuah Catatan Perjalanan di Pedalaman Kalimantan. Yogyakarta: ISI yogyakarta.

Jones, Pip, 2003. Pengantar Teori-Teori Social: Dari Teori Fungsionalisme Hingga Post Modernisme. (terjemahan) Saifuddin. Jakarta: Pustaka Obor.
Juliet Corbin, Anselm Strauss. 2009. Dasar-dasar Penelitian Kualitatif . Yogyakarta: Pustaka Pelajar.

Kaelan, 2012. Metode Penelitian Kualitatif Interdisipliner. Yogyakarta: Penerbit Paradigma.

Kusnawan, Endra. 2019. Sejarah Bekasi: Sejak Peradaban Buni Hingga Wayah Gini. Bogor: Herya Media.

Lissandhi, Ayu Nova. 2014. Skripsi: Kesenian Ondel-ondel: Studi Dinamika dalam kelompok Etnis Betawi di Jakarta.

Merriam, Alan P. 1964. The Anthropology of Music, Terj. Bramantyo Chicago: North-westrn University Press.

Moleong, J.Lexy. 2018. Metode Kualitatif Bandung Penelitian: PT. Remaja Rosdakarya.

M Junus, Melalatoa. 1995. Betawi dalam Ensiklopedi Suku Bangsa Indonesia. Jilid A-K Jakarta: Departemen Pendidikan dan Kebudayaan.

Nettl, Bruno. 2010. Nettls Elephant: On the History of Etnomusicology, urban dan Chicago America: University of Illinois Press.

Oktaviela, Jibrilla. 2017. Skripsi : Lagu Ondel-Ondel Dalam Kelompok Kesenian Renggong Manis Di Jakarta.

Paramita, Sinta. 2018. Journal : Pergeseran Makna Budaya OndelOndel Pada Masyarakat Betawi Modern. Bakti Masyarakat Indonesia.

Prier SJ, Karl Edmund. 1993. Ilmu Bentuk Analisa Musik. Yogyakarta: Pusat Buku.

Rice, Timothy. 2014. Ethnomusicology: A Very Short Introduction. United Kingdom: Oxford University Press.

Rondhi, Mohammad. 2014. Journal: "Fungsi Seni bagi Kehidupan Manusia”. Vol VII 
Saidi, Ridwan. 2002. Ragam Budaya Betawi Vol 15. Jakarta: Dinas Kebudayaan dan Permuseuman DKI Jakarta.

Storey, John. Cultural Theory and Popular Culture: Fifth Edition. New York: Roudledge.

Suryabrata, Sumadi. 1991. Metode Penelitian Jakarta: Rajawali Press.

Yanuar Aji, Adi. Makalah: Mengungkap sisi lain kota Bekasi. 